LA-14022-MS

Approved for public release;

distribution is unlimited.

Density Prediction of Uranium-6 Niobium Ingots 
Los Alamos National Laboratory, an affirmative action/ equal opportunity employer, is operated by the University of California for the United States Department of Energy under contract W-7405-ENG-36.

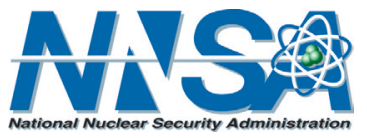

This report was prepared as an account of work sponsored by an agency of the United States Government. Neither the Regents of the University of California, the United States Government nor any agency thereof, nor any of their employees make any warranty, express or implied, or assume any legal liability or responsibility for the accuracy, completeness, or usefulness of any information, apparatus, product, or process disclosed, or represent that its use would not infringe privately owned rights. Reference herein to any specific commercial product, process, or service by trade name, trademark, manufacturer, or otherwise does not necessarily constitute or imply its endorsement, recommendation, or favoring by the Regents of the University of California, the United States Government, or any agency thereof. The views and opinions of authors expressed herein do not necessarily state or reflect those of the Regents of the University of California, the United States Government, or any agency thereof. Los Alamos National Laboratory strongly supports academic freedom and a researcher's right to publish; as an institution, however, the Laboratory does not endorse the viewpoint of a publication or guarantee its technical correctness. 
LA-14022-MS

Issued: April 2003

Density Prediction of Uranium-6 Niobium Ingots
D. F. Teter
P. K. Tubesing
D. J. Thoma
E. Peterson

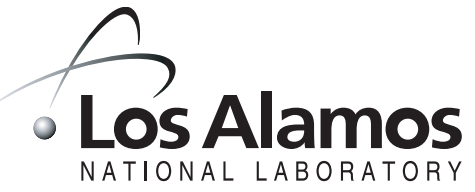





\title{
DENSITY PREDICTION OF URANIUM-6 NIOBIUM INGOTS
}

By

\author{
D.F.Teter, P.K.Tubesing, D.J. Thoma, and E. Peterson, MST-6
}

\begin{abstract}
The densities of uranium-6 niobium (U-Nb) alloys have been compiled from a variety of literature sources such as Y-12 and Rocky Flats datasheets. We also took advantage of the 42 well-pedigreed, homogeneous baseline U-Nb alloys produced under the Enhanced Surveillance Program for density measurements. Even though U-Nb alloys undergo two-phase transitions as the $\mathrm{Nb}$ content varies from $0 \mathrm{wt} . \%$ to $8 \mathrm{wt} \%$, the theoretical and measured densities vary linearly with $\mathrm{Nb}$ content. Therefore, the effect of $\mathrm{Nb}$ content on the density was modeled with a linear regression. From this linear regression, a homogeneous ingot of $\mathrm{U}-6 \mathrm{wt} . \% \mathrm{Nb}$ would have a density of $17.382 \pm 0.040 \mathrm{~g} / \mathrm{cc}(95 \% \mathrm{CI})$. However, ingots produced at $\mathrm{Y}-12$ are not homogeneous with respect to the $\mathrm{Nb}$ content. Therefore, using the $95 \%$ confidence intervals, the density of a Y-12 produced ingot would vary from $17.310 \pm 0.043 \mathrm{~g} / \mathrm{cc}$ at the center to $17.432 \pm$ $0.039 \mathrm{~g} / \mathrm{cc}$ at the edge. Ingots with larger $\mathrm{Nb}$ inhomogeneities will also have larger variances in the density.
\end{abstract}

John Benner, ESA-WR, has requested MST-6 perform an evaluation of the best estimate of the density of U6Nb ingots that can be produced by $\mathrm{Y}-12$.

The densities of U-Nb alloys have been compiled from a variety of literature sources such as Y-12 and Rocky Flats datasheets. We also took advantage of the 42 well-pedigreed, homogeneous baseline U-Nb alloys produced under the Enhanced Surveillance Program for density measurements. Theoretical x-ray and neutron densities, shown in Figure 1 from measurements of these alloys, were considered to evaluate the trends of density with composition. Typically, theoretical densities are not a good measure for actual part densities because the actual part will have a lower density due to defects such as porosity, dislocations, grain boundaries and twins. This is illustrated by comparing the immersion density measurements done by MST- 6 with the calculated theoretical densities from x-ray and neutron diffraction measurements, see Figure 2 . The measured densities are $\sim 2 \%$ lower than the theoretical densities.

For the purposes of this report, the data used for the analysis are only the measured values in Table 1. Unfortunately, most of the published reports do not provide information regarding the technique used for the density value. If the method was not reported, our assumption is that the density value comes from immersion density measurements. However, it is possible that the density value was measured with an alternative technique or calculated from x-ray diffraction data. 
An additional concern with this analysis is in the accuracy of the $\mathrm{Nb}$ concentration measurement. Some of the literature sources are unclear as to whether the composition is a nominal composition or a measured composition. Also, the homogeneity of the material evaluated is in question. U-6 Nb material from Y-12 is usually heavily banded and Rocky Flats material is less banded. Also, if the material used for analysis was a special laboratory ingot, it may have no banding. No mention of homogeneity was given in any of the reports. The 42 baseline alloys produced by MST- 6 are homogeneous and have been accurately measured using chemical analysis. Due to the high pedigree that exists, these alloys would be the best source for further studies of the measured densities to use in calculations of average densities in parts with varying $\mathrm{Nb}$ content.

The theoretical $\mathrm{x}$-ray and neutron density follows a linear relationship with $\mathrm{Nb}$ composition up to about $7 \% \mathrm{Nb}$ as shown in Figure 1. Therefore, for this analysis a linear regression was applied to the data up to U-7.1Nb. Figure 3 shows the fitted regression and the $95 \%$ confidence and prediction limits. The equation for the fitted regression is:

$$
\rho(g / c c)=18.998-0.26926 \times(w t . \% N b) .
$$

The standard errors on the intercept and slope are 0.0274 and 0.00575 respectively. Therefore, a homogeneous ingot of U-6 Nb would have a density of $17.382 \pm 0.040 \mathrm{~g} / \mathrm{cc}(95 \% \mathrm{CI})$. However, recent results from the $\mathrm{Y}-12$ production line show that the $\mathrm{Nb}$ composition is not homogeneous and varies approximately $0.25 \% \mathrm{Nb}$ between the ingot center and edge.

Chemical analysis on a U-6Nb vacuum induction melting, vacuum arc remelt (VIM-VAR-VAR) ingot has been performed as a function of position along the radius of the ingot and also along the length of the ingot under the current special induction engineering release (SIER) to evaluate whether the new process replicates the old process, VIM-Skull-VAR. The Nb composition is highest in the center of the ingot and lowest at the edge. Also, along the length of the ingot the $\mathrm{Nb}$ content is highest at the top and lowest at the bottom. For purposes of calculating the potential density variation existing in a VIM-VAR-VAR ingot, the $\mathrm{Nb}$ composition at the center was analyzed along the length of the ingot to give a high-end average and standard deviation while the edge of the ingot was analyzed along the length of the ingot to give a low-end average and standard deviation. Table 2 summarizes these results. An upper- and lower-bound $\mathrm{Nb}$ content was determined by adding one standard deviation to the center mean $\mathrm{Nb}$ content and by subtracting one standard deviation from the edge mean $\mathrm{Nb}$ content. The $95 \%$ confidence and prediction limits were then calculated at these two extremes in $\mathrm{Nb}$ content to give a range of possible densities. These results are summarized in Table 3. If during production the $\mathrm{Nb}$ composition varies larger than this, then the density variations will also be larger.

Therefore, using the $95 \%$ confidence interval, the density of a $\mathrm{Y}-12$ produced ingot would vary from $17.310 \pm 0.043 \mathrm{~g} / \mathrm{cc}$ at the center to $17.432 \pm 0.039 \mathrm{~g} / \mathrm{cc}$ at the edge.

To provide more confidence in the predicted density of $\mathrm{Y}-12$ produced material, further measurements should be performed on the 42 baseline U-Nb alloys and Y-12 produced material using the immersion and ultrapycnometry techniques. Also, the effect of impurities and inclusion content should be determined to better understand the resulting density variation. 


\section{References:}

1. W.D. Drotning, Ed., J. High Temperatures-High Pressures, 14, 253-258 (1982).

2. V.C. Hemperly, Ed., "Y-12 Technical Datasheets," Union Carbide Corporation, Oakridge, TN, (1978).

3. R.J. Jackson, Ed., Rocky Flats Materials Datasheets," Dow Chemical USA, Rocky Flats Division [RFP-1700, RFP-1681, RFP-1613] (1978).

4. " LASL Shock Hugoniot Data," S.P. Marsh, Ed., (University of California Press, Berkeley, CA, 1980). 


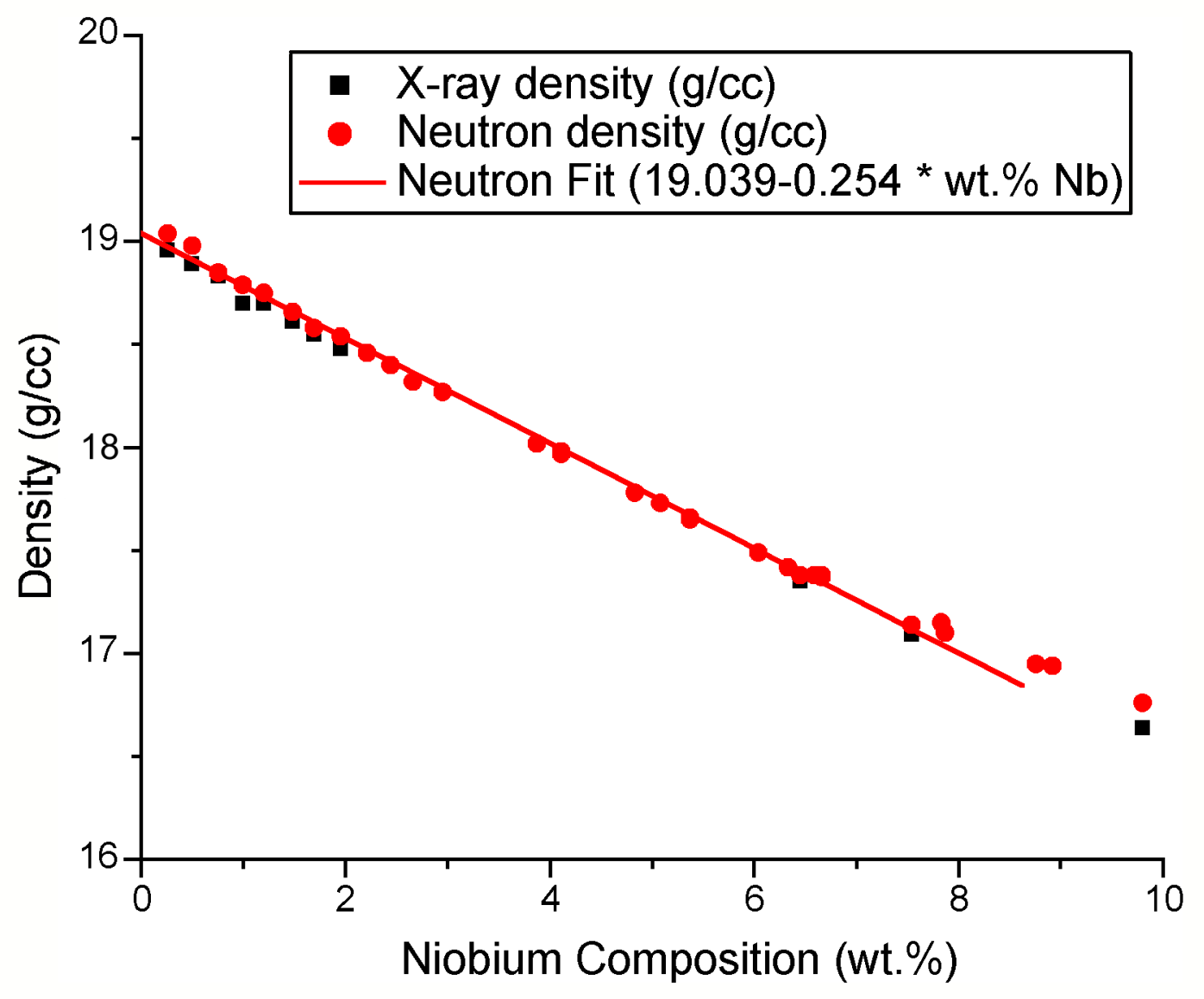

Figure 1: Calculated theoretical densities from $x$-ray and neutron diffraction measurements of homogeneous $\mathrm{U}-\mathrm{Nb}$ alloys. 


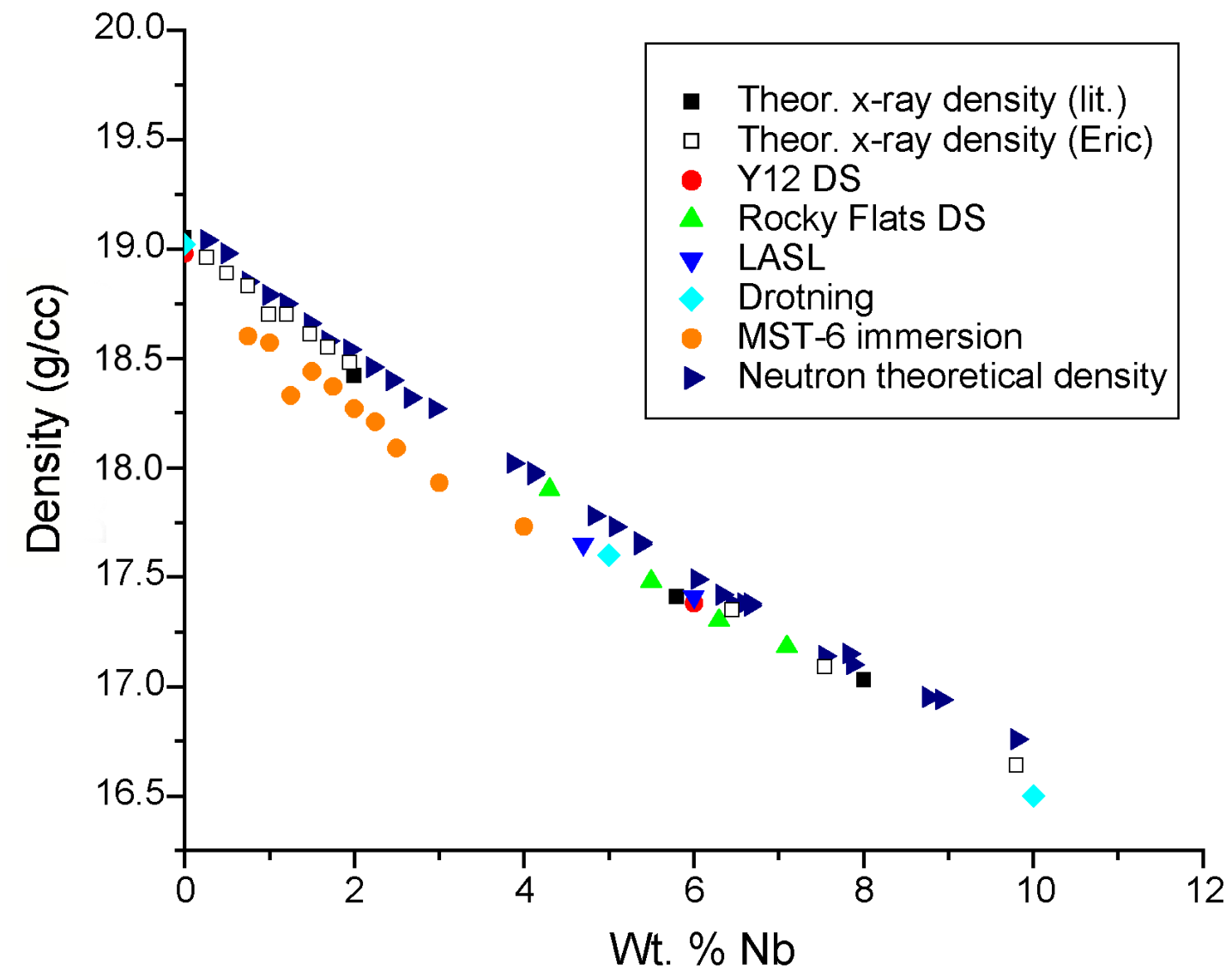

Figure 2: Plot of all sources of density of U-Nb alloys (calculated and measured). 


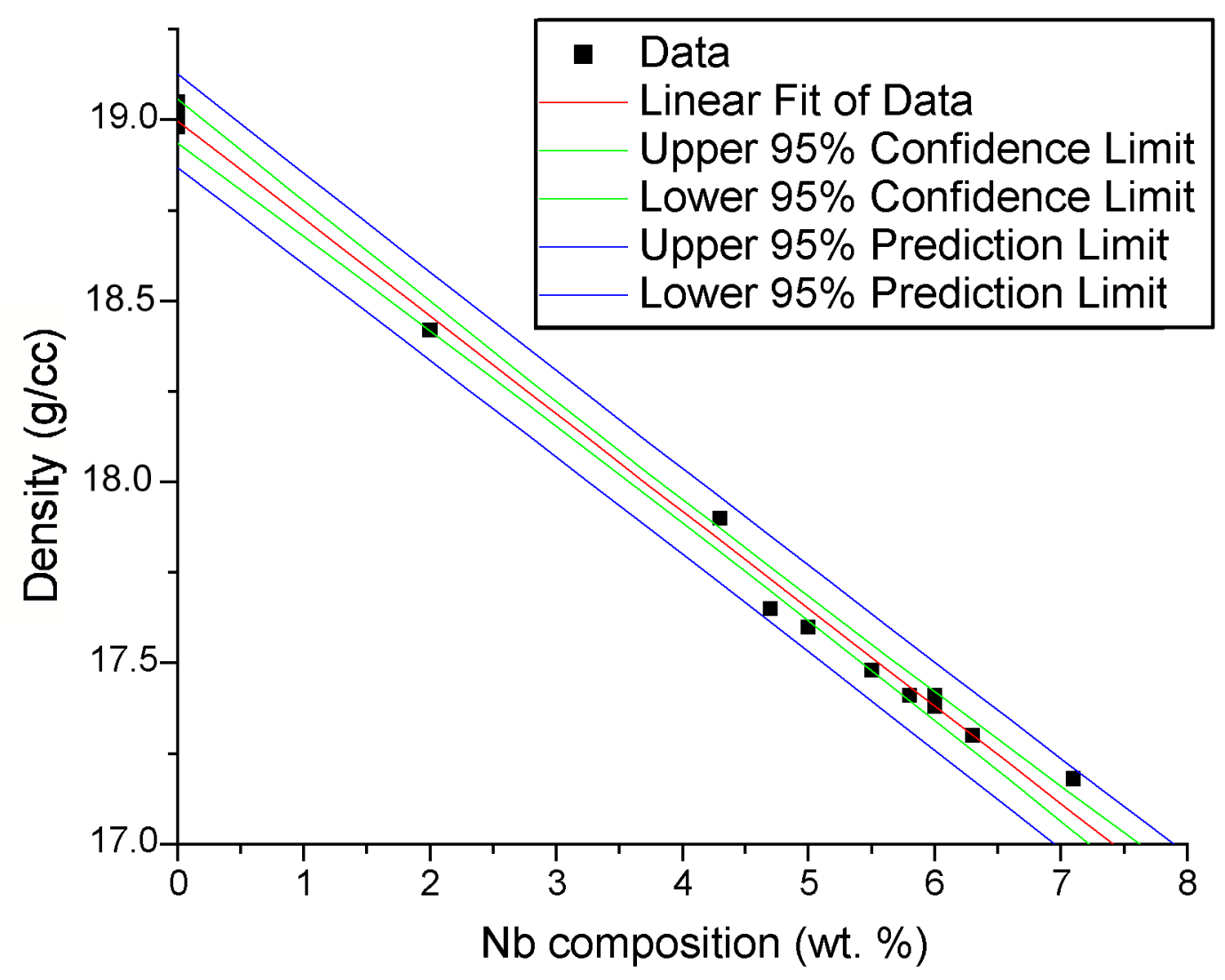

Figure 3: Linear regression of the densities of U-Nb alloys 
Table 1: Densities of U-Nb alloys.

\begin{tabular}{|c|c|c|}
\hline Nb Composition (wt. \%) & Density $(\mathrm{g} / \mathrm{cc})$ & Source \\
\hline 0 & 19.02 & {$[1]$} \\
\hline 0 & 19.05 & Theor. x-ray \\
\hline 0 & 18.98 & {$[2]$} \\
\hline 2 & 18.42 & Theor. x-ray \\
\hline 4.3 & 17.9 & {$[3]$} \\
\hline 4.7 & 17.65 & {$[4]$} \\
\hline 5 & 17.6 & {$[1]$} \\
\hline 5.5 & 17.48 & {$[3]$} \\
\hline 5.8 & 17.41 & Theor. x-ray \\
\hline 6 & 17.411 & {$[4]$} \\
\hline 6 & 17.38 & {$[2]$} \\
\hline 6.3 & 17.3 & {$[3]$} \\
\hline 7.1 & 17.18 & {$[3]$} \\
\hline
\end{tabular}

Table 2: Chemistry variation within a U-6Nb VIM-VAR-VAR ingot.

\begin{tabular}{|lcc|}
\hline Location & Mean Nb Content & Standard Deviation \\
\hline Center of ingot, $\mathbf{1}^{\text {st }}$ target & 6.120 & 0.150 \\
\hline Edge of ingot, $\mathbf{6}^{\text {th }}$ target & 5.857 & 0.040 \\
\hline
\end{tabular}

Table 3: 95\% Confidence and prediction limits

\begin{tabular}{|c|c|c|c|c|}
\hline & & \multicolumn{3}{|c|}{ Density $95 \%$ Confidence Intervals } \\
\hline & $\mathrm{Nb}$ Content & UCL & mean & LCL \\
\hline Center, mean + 1stdev & 6.270 & 17.352 & 17.310 & 17.267 \\
\hline \multirow[t]{3}{*}{ Edge, mean - 1stdev } & 5.817 & 17.470 & 17.432 & 17.393 \\
\hline & & \multicolumn{3}{|c|}{ Density $95 \%$ Prediction Intervals } \\
\hline & & UCL & mean & $\mathrm{LCL}$ \\
\hline Center, mean + 1stdev & 6.270 & 17.432 & 17.310 & 17.188 \\
\hline Edge, mean - 1stdev & 5.817 & 17.552 & 17.432 & 17.311 \\
\hline
\end{tabular}


This page left blank intentionally. 
This page left blank intentionally. 
This page left blank intentionally. 
This report has been reproduced directly from the best available copy. It is available electronically on the Web (http://www.doe.gov/bridge).

Copies are available for sale to U.S. Department of Energy employees and contractors from:

Office of Scientific and Technical Information P.O. Box 62

Oak Ridge, TN 37831

(865) 576-8401

Copies are available for sale to the public from: National Technical Information Service

U.S. Department of Commerce

5285 Port Royal Road

Springfield, VA 22616

(800) 553-6847 


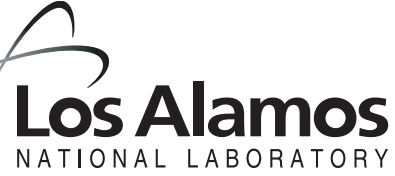

Los Alamos NM 87545 